\title{
Occupational asthma due to ceftazidime
}

\author{
S.C. Stenton, J.H. Dennis*, D.J. Hendrick
}

\begin{abstract}
Occupational asthma due to ceftazidime. S.C. Stenton, J.H. Dennis, D.J. Hendrick. (C)ERS Journals Ltd 1995.

ABSTRACT: A worker employed in the manufacture of the new third generation cephalosporin antibiotic, ceftazidime, developed asthmatic symptoms, and a series of inhalation challenge tests was undertaken to investigate the problem.

The inhalation of increasing daily doses of ceftazidime up to $3.2 \mathrm{mg}$, using a double-blind challenge protocol gave rise to symptoms, late asthmatic reactions, and increases in airway responsiveness to methacholine. A repeat challenge with the $3.2 \mathrm{mg}$ dose additionally gave rise to a clear immediate reaction. Ceftazidime was, thus, shown to be capable of inducing occupational asthma.

Eur Respir J., 1995. 8. 1421-1423.
\end{abstract}

Chest Unit and Regional Unit for Occupational Lung Disease, Newcastle General Hospital, University of Newcastle-upon-Tyne, UK. *Currently at: Dept of Environmental Science, University of Bradford, UK.

Correspondence: S.C. Stenton

Chest Unit

Newcastle General Hospital University of Newcastle-upon-Tyne Newcastle-upon-Tyne

UK

Keywords: Airway responsiveness, ceftazidime, methacholine, occupational asthma

Received: November 91994

Accepted after revision April 111995
Occupational asthma is a potential hazard associated with the manufacture of a wide variety of pharmaceutical agents, including antibiotics, histamine-2-antagonists, laxatives, emetics, and even intermediates in the manufacture of salbutamol [1-3]. Asthma due to first and second generation cephalosporin antibiotics has been reported previously [4]. This paper describes the first case of occupational asthma due to ceftazidime, a third generation cephalosporin antibiotic.

\section{Case report}

A 22 year old nonsmoking female, with no previous personal or familial history of asthma, was employed in the manufacture and packaging of ceftazidime. Although most of the manufacturing operations were fully enclosed, she experienced occasional exposures to powdered ceftazidime during maintenance and repair operations. After a period of approximately one year, she developed rhinitis which appeared to be work-related. Shortly afterwards, she suffered three episodes of mild wheezing. The first occurred during the night, lasted approximately $30 \mathrm{~min}$ and resolved spontaneously allowing her to return to sleep. It did not appear to follow any unusual exposures during the preceding day at work. The second episode occurred during a weekend, whilst she was out walking, and again resolved spontaneously. The third episode occurred when at work but was not obviously associated with any unusual occupational exposures. On this occasion, salbutamol was administered for the relief of symptoms.

At presentation, ventilatory function was normal (forced expiratory volume in one second (FEV1) 3.6 L, 98\% of predicted) but the provocative dose of methacholine producing a $20 \%$ decrease in FEV1 (PD20FEV1) was 500 $\mu \mathrm{g}$, indicating a moderate degree of airway hyperresponsiveness consistent with mildly active asthma [5]. Skinprick tests to common aeroallergens were all negative.

A workplace challenge test was arranged after a 2 week holiday. There were no unusual occupational exposures and the return to work was not accompanied by any immediate symptoms, obvious asthmatic reactions or increases in airway responsiveness (table 1). However, mild symptoms and an increase in airway responsiveness did recur 1 week later after a period of routine maintenance work. A series of laboratory challenges was then arranged to clarify the diagnosis and to obtain an estimate of the threshold exposures likely to trigger asthmatic reactions.

\section{Inhalation challenge tests}

The challenge doses were based on exposure measurements in the workplace. The starting dose for the series was $0.32 \mu \mathrm{g}$, approximately one hundredth of the dose which had been encountered at work without causing symptoms. A single challenge was administered each day, daily dose increments of $\times 3.2(\sqrt{ } 10)$ were used, and control challenges with phenol-saline were interspersed at random in a double-blind manner. Thus, neither the subject nor the immediately supervising physician were aware of the precise dose being administered each day, or whether a saline control was being used. The maximum challenge dose was chosen to be $3.2 \mathrm{mg}$, as a failure to react to that dose would have made the diagnosis of occupational asthma due to ceftazidime very unlikely. To ensure that the reaction to this dose was reproducible, it was repeated. 
Table 1. - Changes in airway responsiveness to methacholine with exposures to ceftazidime

\begin{tabular}{|c|c|c|c|}
\hline Time & & Exposure & $\begin{array}{c}\text { PD20FEV1 } \\
\mu \mathrm{g}\end{array}$ \\
\hline Initi & evaluation & At work & 500 \\
\hline Wor & place challe & ge study & \\
\hline Day & -8 & After 2 week holiday & $>6400$ \\
\hline & -7 & & $>6400$ \\
\hline & 1 & Returned to work & $>6400$ \\
\hline & 7 & Machine stripping & 4000 \\
\hline & 8 & & 2300 \\
\hline & 9 & & 275 \\
\hline Lab & atory chall & lge study & \\
\hline Day & -5 & Off work 10 days & 900 \\
\hline & -1 & Off work 2 weeks & 2350 \\
\hline & 0 & & 3200 \\
\hline & 23 & After ceftazidime $3.2 \mathrm{mg}$ & 30 \\
\hline & 24 & & 30 \\
\hline & 25 & & 140 \\
\hline & 29 & $\begin{array}{l}\text { After further ceftazidime } \\
3.2 \mathrm{mg}\end{array}$ & 4 \\
\hline & 30 & & 85 \\
\hline & 51 & At work, not exposed & 1080 \\
\hline
\end{tabular}

PD20FEV1: provocative dose of methacholine producing a $20 \%$ decrease in forced expiratory volume in one second.

The decision whether to challenge with ceftazidime or with a saline control was made each morning by a physician not directly involved with the challenges. Solutions of ceftazidime in $0.4 \%$ phenolsaline were prepared immediately prior to each challenge by a technician using a serial dilution technique. All challenge doses were administered at 10.00 a.m. using an inhalation dosimeter [6], which controls the nebulised dose delivered to the subject to within $\pm 10 \%$. Phenol was added to disguise any smell/taste of the challenge solutions.

Ventilatory function was monitored as FEV1 using a wedge bellows spirometer (Vitalograph, Bucks, UK). The mean of three FEV1 measurements was recorded at 10 min intervals from 9.20 to 10.00 a.m. to establish a baseline for that day, at $10 \mathrm{~min}$ intervals from 10.00 to 11.20 a.m. to detect any immediate asthmatic reaction, and then hourly from 12.00 noon until 10.00 p.m. to detect any late asthmatic reaction. Further measurements were recorded at 8.00, 9.00 and 10.00 a.m. the following morning. Measurements were made at identical times on three control days prior to any challenge to establish the normal circadian pattern of ventilatory function. On each active challenge day, the subject was observed in the laboratory until the danger of any immediate reaction had passed and then allowed home, remaining in telephone contact with the supervising physician. All respiratory symptoms over the $24 \mathrm{~h}$ monitoring period were recorded.

Airway responsiveness was measured using a dosimeter technique before and after the series of inhalation challenges [6]. Following baseline FEV1 measurements, doubling cumulative doses of methacholine (3.125-6,400 $\mu \mathrm{g})$ were administered at $5 \mathrm{~min}$ intervals until a fall in FEV 1 of at least $20 \%$ was recorded. The PD20FEV1 was calculated by linear interpolation from the dose-response plot.
The magnitude of late changes in ventilatory function was quantified as the area between a line extrapolated from the mean baseline for the day and the actual measurements $2-12 \mathrm{~h}$ postchallenge (the $2-12 \mathrm{~h}$ area decrement (AD)). The statistical significance of the late changes was determined by comparing the ADs on the active challenge days against those on the three prechallenge control days, and by comparing individual hourly FEV1 measurements against a lower boundary for hourly measurements on control days [7]. The lower boundary describes the lowest FEV1 which would be expected by chance at each hour if ventilatory function behaves in the same way on an active challenge day as it did on control days.

\section{Results}

The subject stayed away from work for 2 weeks before the tests, during which time there was a substantial decrease in airway responsiveness (table 1). Symptoms of rhinitis were noted immediately after all challenges with ceftazidime doses above $10 \mu \mathrm{g}$. Symptoms of chest tightness and wheezing together with late falls in FEV1 were first observed following the 1 and $3.2 \mathrm{mg}$ challenges. The $\mathrm{AD}$ measurements following the active ceftazidime challenges showed a suggestion of a dose-response relationship at the higher challenge doses (fig. 1). The late falls in FEV1 following the $3.2 \mathrm{mg}$ challenges were statistically significant $(\mathrm{p}<0.05)$ (figs. 1 and 2$)$. There was a suggestion of an immediate asthmatic reaction following the $1 \mathrm{mg}$ challenge and the initial $3.2 \mathrm{mg}$ challenge, and there was a clear immediate reaction after the repeat $3.2 \mathrm{mg}$ challenge (fig. 2).

There was a considerable temporary increase in airway responsiveness following the challenge series, PD20FEV1 decreasing from 3,200 $\mu \mathrm{g}$ before exposure to $4.4 \mu \mathrm{g}$ on the day immediately afterwards (table 1).

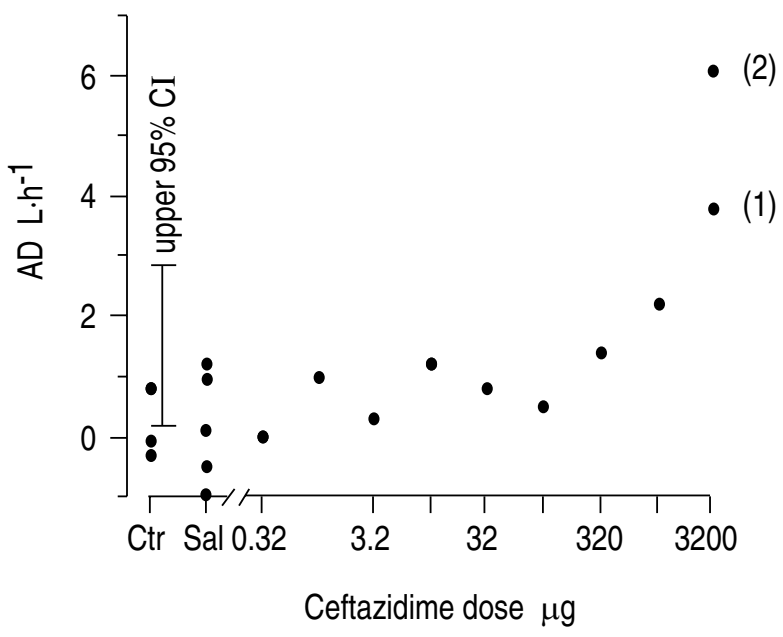

Fig. 1. - A-D (area decrement) for control, post-saline and post-ceftazidine provocation. Prechallenge control measurements are shown together with their upper 95\% confidence interval (95\% CI). Saline control measurements are shown separately, as they might have been influenced by carry-over effects from previous active challenges. (1) and (2) denote the first and second ceftazidime provocation at a dose of $3.2 \mathrm{mg}$. FEV1: forced expiratory volume in one second Ctr: control; Sal: saline. 


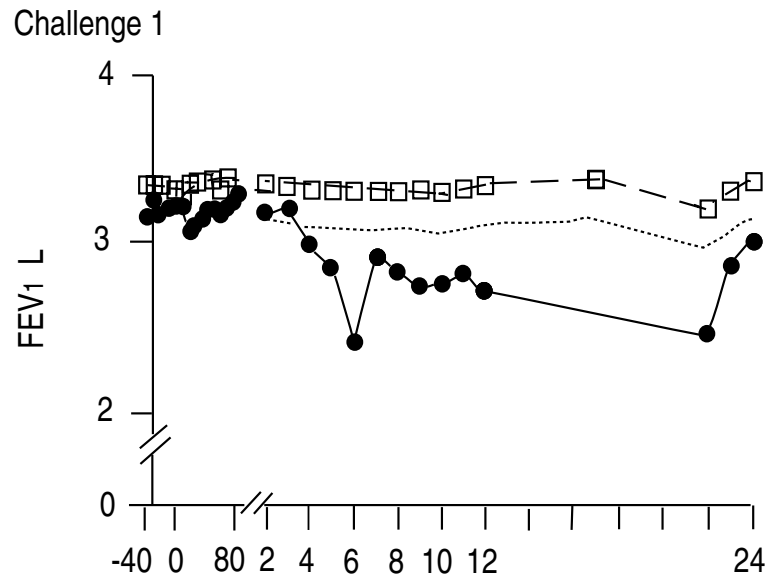

Challenge 2

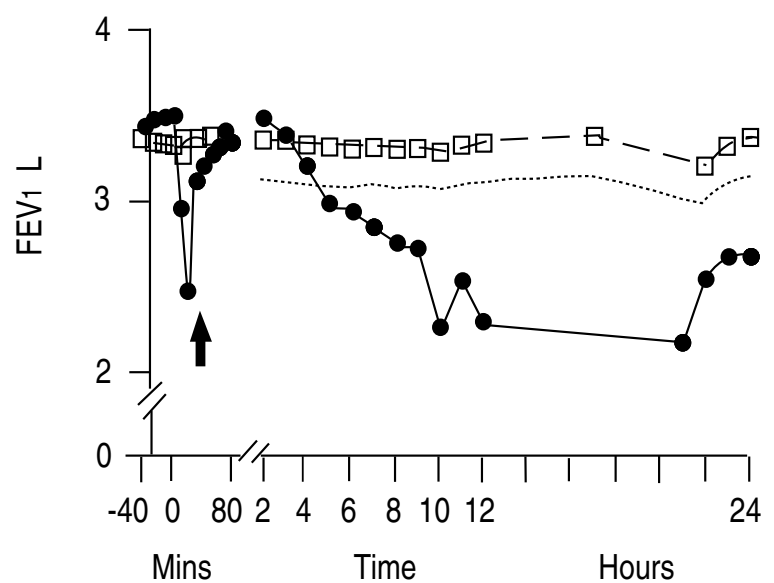

Fig. 2. - Effect of ceftazidime (3.2 mg) on FEV1 on 2 challenge days 1 week apart. There were marked late reactions: No FEV1 measurements should cross the boundaries if lung function is behaving in the same way on challenge days as it did on control days. There was a marked difference in the magnitudes of the immediate responses on the two challenge days. Salbutamol (arrow) was necessary following the second challenge. $\square-\square$ : mean of three control days; : lower boundary for control days; $\bullet \bullet$ : ceftazidime $3.2 \mathrm{mg}$. FEV 1 : forced expiratory volume in one second. Note that the vertical axes are cut off from zero.

\section{Discussion}

The asthma symptoms, immediate and late falls in FEV1 and increases in airway responsiveness seen in this double blind study clearly demonstrated that occupational exposures to ceftazidime are capable of inducing occupational asthma. The case illustrates the value of a high index of suspicion for occupational asthma and of early referral and investigation. A firm diagnosis was established, despite the very minimal symptoms at presentation. There had been only three episodes of wheezing and only one of these bore any obvious relation to occupational exposures. The significance of these symptoms might well have been overlooked, particularly if the rhinitis, which was more closely related to ceftazidime exposures, had not been present. The establishment of a firm diagnosis allowed this subject to be moved to another part of the manufacturing plant where further exposure could be avoided. As the likelihood of recovery from occupational asthma is related to the duration of the period of symptomatic exposure [8], this early diagnosis offered the best opportunity for an optimal outcome.

The case also illustrates the usefulness of airway responsiveness measurements in evaluating possible occupational asthma. Very marked changes in PD20FEV1 were noted in association with occupational and laboratory exposures to ceftazidime, and these strongly supported the diagnosis. Such rapid and very marked changes in airway responsiveness are only rarely seen in non-occupational asthma, the PD20FEV1 normally being repeatable within $30-300 \%$ of an initial measurement [6].

The demonstration of a marked immediate asthmatic reaction following the second challenge with ceftazidime $3.2 \mathrm{mg}$ is of some interest. This second challenge was performed 1 week after the first, which had given rise to a late asthmatic reaction with no more than a hint of an immediate response. At the time of the second 3.2 $\mathrm{mg}$ challenge, the level of airway responsiveness had been increased as a consequence of the previous challenge. It is possible that a specific immune response might also have been primed by this challenge. The demonstration of late asthmatic reactions at doses lower than those which provoke immediate reactions suggests that the mechanism of the late reaction is largely independent of any preceding immediate reaction, even when the two occur together. It also suggests that the development of any asthmatic reaction (whether immediate, late, or dual) depends more on the challenge dose, (or the level of occupational exposure), and the degree of airway responsiveness, than on any inherent property of the occupational agent.

\section{References}

1. Stenton SC, Hendrick DJ. Occupational asthma. Postgrad Med J 1991; 67: 271-277.

2. Davies RJ, Hendrick DJ, Pepys J. Asthma due to inhaled chemical agents: ampicillin, benzyl penicillin, aminopenicillinic acid and related substances. Clin Allergy 1974; 4: 227-247.

3. Fawcett IW, Pepys J, Erooga MA. Asthma due to "glycyl compound" powder, an intermediate in the production of salbutamol. Clin Allergy 1976; 6: 405-409.

4. Couts II, Dally MB, Newman-Taylor AJ, Pickering CAC, Horsfield N. Asthma in workers manufacturing cephalosporins. Br Med J 1981; 283: 950.

5. Stenton SC, Beach JR, Avery AJ, Hendrick DJ. The value of questionnaires and spirometry in asthma surveillance programmes in the workplace. Occup Med 1993; 43: 203-206.

6. Beach JR, Young CL, Stenton SC, et al. Measurement of airway responsiveness to methacholine: the relative importance of the precision of drug delivery and the method of assessing the response. Thorax 1993; 48: 133-135.

7. Stenton SC, Avery AJ, Walters EH, Hendrick DJ. Statistical approaches to the identification of late asthmatic reactions. Eur Respir J 1994; 7: 806-812.

8. Chan-Yeung M, Lam S, Korner S. Clinical features and natural history of occupational asthma due to Western Red Cedar (Thuja plicata). Am J Med 1982; 72: 411-415. 